\title{
Anesthetic Management of a 9-day-old Neonate with Intestinal Evisceration due to Dog Bite
}

\author{
${ }^{1}$ Sowmya M Jois, ${ }^{2}$ Kallur Thimmarayappa Venkatesh Murthy, ${ }^{3}$ Sunand Ankitha, ${ }^{4}$ Hiremathada Sahajananda
}

\begin{abstract}
Intestinal evisceration following dog bite is rare in neonates. We report a successful anesthetic management of a 9-day-old neonate who was brought to our emergency room with history of stray dog bite 1 hour before presenting. Baby was posted for emergency exploratory laparotomy and procedure.
\end{abstract}

Keywords: Dog bite, Intestinal evisceration, Neonate.

How to cite this article: Jois SM, Murthy KTV, Ankitha S, Sahajananda H. Anesthetic Management of a 9-day-old Neonate with Intestinal Evisceration due to Dog Bite. J Med Sci 2017;3(4):111-112.

\section{Source of support: Nil}

Conflict of interest: None

\section{INTRODUCTION}

Dog bite is common in pediatric population both in developed and developing countries and causes significant morbidity. Visceral injuries are rare due to dog bite. There are reports of bowel evisceration with contusion of bowel with serosal tear. ${ }^{1}$ The anesthetic considerations in neonatal surgical emergencies are based on the physiological immaturity of various body systems, poor tolerance of the anesthetic drugs, associated congenital disorders, and considerations regarding the use of high concentration of oxygen. The main goal is titration of anesthetics to desired effects while carefully monitoring the cardiorespiratory status. ${ }^{2}$

\section{CASE REPORT}

A 9-day-old baby was presented to the operation room for emergency laparotomy and procedure. Parents gave history that the baby was bitten by an unprovoked stray $\operatorname{dog} 1$ hour back in their house following which there was bleeding from the wound and protrusion of bowel from one of the wounds. No preexisting cardiorespiratory

\footnotetext{
${ }^{1}$ Senior Resident, ${ }^{2}$ Professor, ${ }^{3}$ Postgraduate Student, ${ }^{4}$ Professor and Head

${ }^{1-4}$ Department of Anesthesiology and Critical Care, RajaRajeswari Medical College \& Hospital, Bengaluru, Karnataka, India

Corresponding Author: Sowmya M Jois, Senior Resident Department of Anesthesiology and Critical Care, RajaRajeswari Medical College \& Hospital, Bengaluru, Karnataka, India, e-mail: drsowmyasharma@gmail.com
}

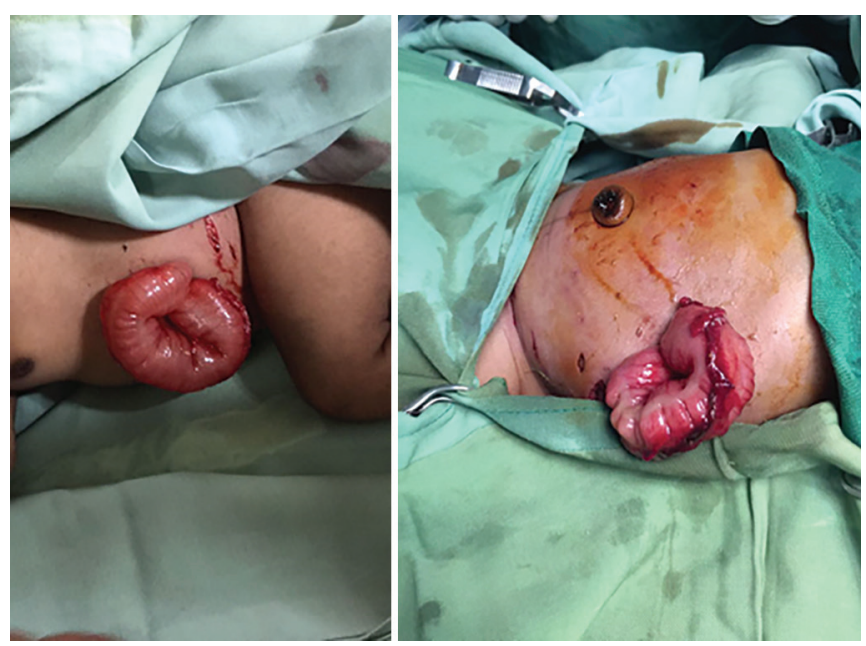

Fig. 1: Newborn with evisceration

dysfunction was found by preanesthetic assessment (Fig. 1).

Mother had regular antenatal care and had taken two tetanus toxoid injections in her second trimester. Baby was born by cesarean section for fetal distress due to umbilical cord round the neck. Birth weight was $2.6 \mathrm{~kg}$. Baby had cried immediately after birth and there were no perinatal problems. Baby was feeding well.

On examination, baby was found to be conscious. There was tachycardia and dehydration. Cardiovascular system and respiratory systems were normal.

On examination, there were multiple lacerated wounds over the abdomen. There was a loop of intestine protruding out of one of the wounds on the left side of the abdomen. Baby was fed with breast milk 2 hours back. Baby was posted for emergency laparotomy and procedure.

Informed consent was taken from parents. Child was started with Ringer's lactate at $12 \mathrm{~mL}$ per hour by $24 \mathrm{G}$ intravenous (IV) cannula with a syringe pump. General anesthesia with endotracheal intubation was planned.

Operation theater was kept ready, and temperature was set to $23^{\circ} \mathrm{C}$. Anesthetic drugs and emergency drugs were kept ready. Anesthesia machine was checked, and appropriate-size endotracheal tubes were kept ready. Warming blanket was placed over the baby. Electrocardiogram, pulse oximetry, noninvasive blood pressure, and temperature probe were connected and monitored. Baseline values were recorded. Basal heart rate was 150 beats per minute, noninvasive blood pressure was $70 / 35 \mathrm{mmHg}, \mathrm{SpO}_{2} 96 \%$, and 
temperature $35.9^{\circ} \mathrm{C}$. An $8 \mathrm{G}$ infant feeding tube was placed nasally. Then, $12 \mathrm{~mL}$ of stomach contents were aspirated by a $10 \mathrm{~mL}$ syringe. Baby received injection glycopyrrolate $0.014 \mathrm{mg}$ IV as premedication. Baby was induced with injection thiopentone, $6 \mathrm{mg}$; injection fentanyl $6 \mu \mathrm{g}$; and muscle relaxant atracurium, $1.5 \mathrm{mg}$ IV. Baby was intubated with size 3 endotracheal tube, bilateral air entry checked, and tube fixed. Baby was ventilated using Jackson Ree's circuit. Anesthesia was maintained with $\mathrm{O}_{2}+$ air (50:50) with sevoflurane (1.5\%). In the intraoperative period, blood loss was around $30 \mathrm{~mL}$. Exposed descending colon was given a thorough wash with normal saline. Bowel was thoroughly inspected for perforation. Wound was closed. There was fall in saturation during vigorous retraction of abdomen which improved after releasing the retraction.

After adequate return of spontaneous breathing, baby was given neostigmine $0.15 \mathrm{mg}$ and injection glycopyrrolate $0.024 \mathrm{mg}$ IV. Baby was extubated and shifted to neonatal intensive care unit for further monitoring. Intravenous antibiotics and IV fluids were continued. Baby received rabies vaccine and rabies immunoglobin as per the standard protocol. After 3 days, oral feeds were started. Baby recovered well and was discharged on the 10th day.

\section{DISCUSSION}

Grazed abrasions and lacerations to the skin are commonly found following animal bite. Among animal bites, dog bites and cat bites are common in children. Injuries caused by animal bites can cause injuries to the soft and hard tissues, presented by perforations, lacerations, crushes, avulsion, or fractures. A lot of bacteria and virus can be found in such injuries, a reason of concern in such injuries. ${ }^{3}$

One such concern is transmission of rabies. Appropriate tetanus and rabies prophylaxis should also be a part of caring for a patient who has sustained a dog bite, as well as local debridement and thorough cleaning of the wound. ${ }^{4}$ Surgical intervention in a patient on antirabies vaccine is a dilemma, as it may cause a reduction in the efficacy of the vaccination through an immunosuppressive effect of anesthesia and surgery. There are very few reports on the safety of anesthesia and surgery in a patient receiving antirabies vaccination. ${ }^{4}$ Adequate perioperative analgesia should be maintained to reduce the chances of immune dysfunction, due to pain and stress of surgery.

Newborns undergoing emergency operations present several difficult challenges for the anesthesiologist. A newborn requires constant vigilance, rapid recognition of the adverse events, and swift intervention during anesthesia. $^{2}$

Important consideration is neonates with full stomach. There is risk of aspiration during induction and extubation. Classical adult type of rapid sequence induction
(RSI) intubation is not always appropriate in children with full stomach. In newborns, infants, and small children, limited cooperation during preoxygenation, reduced respiratory oxygen reserves, increased oxygen demand, and a tendency for airway collapse easily lead to hypoxemia after induction of anesthesia. Application of cricoid pressure does not reliably prevent pulmonary aspiration. It also distorts the airway leading to difficult mask ventilation and difficult intubation.

In children, cricoid pressure provokes bucking and straining, and therefore, should not be routinely used. Key features of RSI intubation for children are effective induction of deep anesthesia followed by profound muscle paralysis, careful mask ventilation, and gentle tracheal intubation under optimized conditions. ${ }^{5}$

Nasogastric tube is essential for gastric decompression and remained on suction during induction and intubation to minimize the amount of gastric contents in the oropharynx. $2,6,7$

Neonates coming for emergency surgery pose risk for anesthesia. Thorough understanding of physiological and pharmacological changes in neonates is important. Multidisciplinary approach by anesthestists, pediatric surgeons, and neonatal intensivists is required for meticulous management of these vulnerable patients.

\section{CONCLUSION}

In our case, we successfully managed a newborn with intestinal evisceration following dog bite who underwent laparotomy and exploration taking all the necessary precautions. Neonates are at high risk for anesthesia and surgery, especially during emergency surgeries. Careful preanesthetic evaluation, adequate preparation, and management were performed by multidisciplinary approach in our case.

\section{REFERENCES}

1. Ameh EA. Major injuries from "domestic" animals in children. Pediatr Surg Int 2000 Nov;16(8):589-591.

2. Pani N, Panda CK. Anaesthetic consideration for neonatal surgical emergencies. Indian J Anaesth 2012 Sep-Oct;56(5): 463-469.

3. Sismao NR, Borba AM, da Silva ALF, Vieira EMM, Carvalhosa $\mathrm{AA}$, Bandeca MC, Borges AH. Animal bite injuries to the face: a case report. J Int Oral Health 2013 Aug;5(4):68-72.

4. Sabhaney V, Goldman RD. Management of dog bites in children. Can Fam Physician 2012 Oct;58(10):1094-1096.

5. Weiss M, Gerber AC. Induction of anesthesia and intubation in children with a full stomach. Time to rethink! Anesthetist 2007 Dec;56(12):1210-1216.

6. Rewari V, Garg R, Trikha A. Rabies vaccine and neuraxial anaesthesia. S Afr J Anaesthesiol Analg 2010 Aug;16(5):32-34.

7. Chandrashekhar S, Davis L, Challands J. Anaesthesia for neonatal emergency laparotomy. Contin Educ Anaesth Crit Care Pain 2015 Aug;15(4):194-198. 